Al Iidara Balad, Vol. 1, No.1, Juli 2019

ISSN 2685-8541

\title{
IMPLEMENTASI PERATURAN DAERAH NOMOR 17 TAHUN 2015 TENTANG PENANGGULANGAN MASALAH GELANDANGAN DAN PENGEMIS (GEPENG) (STUDY KASUS DI KECAMATAN BANJANG KABUPATEN HULU SUNGAI UTARA)
}

\author{
SITI RAUDAH \\ Dosen Tetap STIA Amuntai \\ siti.raudah8@gmail.com
}

\begin{abstract}
Implementation of Regional Regulation Number 17 Year 2015 on Efforts to Overcome Problems of Villagers and Beggars (Case Study in Banjang Sub-District Hulu Sungai Utara). The increasing number of homeless and beggars in Amuntai City of Hulu Sungai Utara Regency is 119 people, and the addition is due to other areas coming from 23 people, that is from Banjarbaru, Tenggarong, Banjarmasin, Malang and Barabai so that the total is all 142. The number will disturb the name of the smooth development of the region, for example, the problem of security and public order.

The purpose of this research is to identify and analyze the implementation of Local Regulation and to analyze the obstacles in implementing Local Regulation Number 17 year 2015 on Efforts to Overcome Problems of Villagers and Beggars in Amuntai City of Hulu Sungai Utara Regency.

The research method is descriptive qualitative, type and source of data that is primary data through observation, interview while secondary data through existing data at Social Service and Satpol PP of Hulu Sungai Utara Regency, technique used in sampling that is Snow-Ball sampling technique snowball sampling).

From the results of the research shows that In the implementation of Regional Regulation Number 17 year 2015 on the Prevention of Problems of Beggars and Beggars in Amuntai City of Hulu Sungai Utara Regency, still not fully implemented, it is seen that shelter houses for street children and homeless shelters are not built when this is an effort in tackling the widespread problem of the Homeless and the Beggar. However, persuasive guidance has been done by the Social Service and Satpol PP at the time of capturing or patrolling for controlling the street children.

The suggestions provided for the input materials include Building Homes for the shelter of homeless and beggars who have no home, and can provide guidance on skills training to be more independent, Must have the attention and support from the Regent of Hulu Sungai Utara related problems the provision of budget funds in terms of supporting efforts to overcome the problems of homeless and beggars in Amuntai City so that security and order be better and achievement of regional development goals.
\end{abstract}

Keywords: Implementation, Countermeasures, Vagrant and Beggar

Siti Raudah | Implementasi Peraturan ..... | 96 


\section{PENDAHULUAAN}

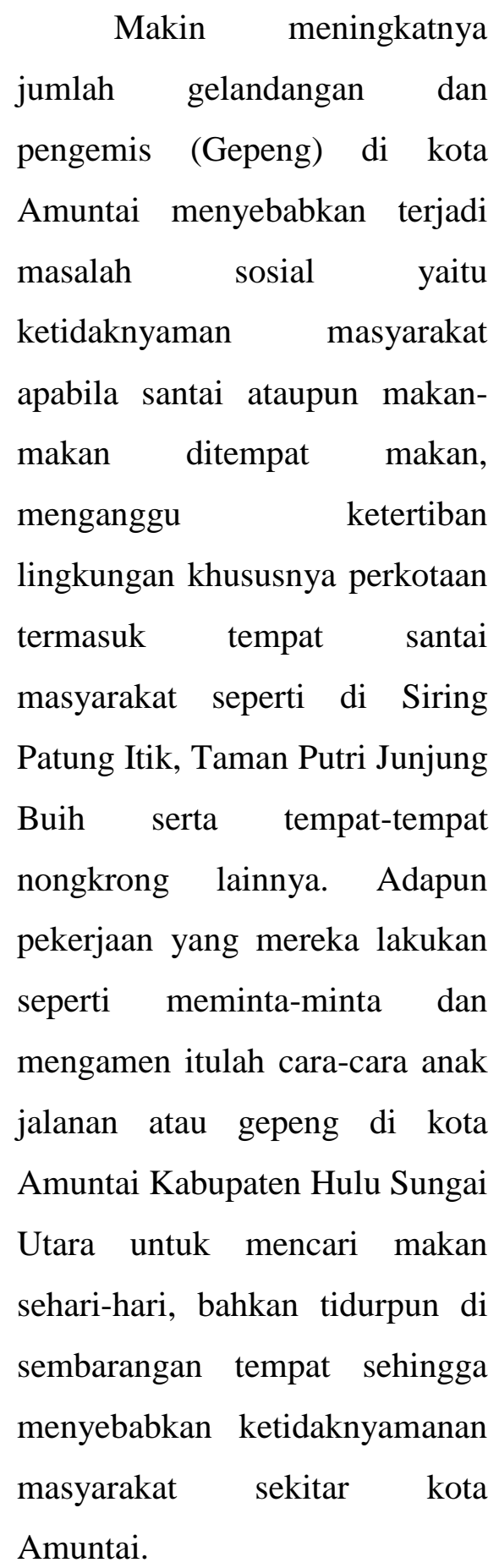

Dari data yang didapat pada Dinas Sosial Kabupaten Hulu Sungai Utara pada Bidang Rehabilitasi Sosial Jumlah Gelandangan dan Pengemis (Gepeng) dari 2016 sebanyak 119 orang namun pada tahun 2017 makin meningkat yaitu penambahan jumlah tersebut sebanyak 23 orang, kemudian total semuanya sebanyak 142 orang. Penambahan jumlah dikarenakan dari daerah lain berdatangan dari jumlah 23 orang, yaitu dari Banjarbaru, Tenggarong, Banjarmasin, Malang dan Barabai.

pah sejak dari rumah, hingga ke Tempat Pembuangan Sampah.

Oleh karena itu maka penulis tertarik untuk melakukan penelitian sejauh mana pelaksanaan penertiban dan pembinaan yang dilakukan oleh pemerintah Kota Amuntai Kabupaten Hulu Sungai Utara terhadap Gelandangan dan Pengemis demi terciptanya ketertiban dan keindahan kota. 
Maka dari itu penulis mengangkat judul penelitian "Implementasi Peraturan Daerah Nomor 17 Tahun 2015 tentang Penanggulangan Masalah Gelandangan dan Pengemis (Gepeng) (Study Kasus di Kecamatan Banjang Kabupaten Hulu Sungai Utara)".

\section{FOKUS PENELITIAN}

Fokus penelitian yaitu mengenai Upaya

Penanggulangan Masalah

Gelandangan dan Pengemis (Gepeng) yang ada di Kecamatan Banjang, sehingga bisa mewujudkan pembangunan daerah yang sesuai dengan tujuan utama Pemerintah Daerah Kabupaten Hulu Sungai Utara.

\section{RUMUSAN MASALAH}

1. Bagaimana Implementasi Peraturan Daerah Nomor 17 Tahun 2015 tentang Penanggulangan Masalah Gelandangan dan Pengemis (Gepeng) di Kecamatan
Banjang Kabupaten Hulu Sungai Utara?

2. Apa saja kendala-kendala yang mempengaruhi keberhasilan Implementasi Peraturan Daerah Nomor 17 Tahun 2015 tentang Penanggulangan Masalah Gelandangan dan Pengemis (Gepeng) di Kecamatan Banjang Kabupaten Hulu Sungai Utara?

\section{TUJUAN PENELITIAN}

a. Untuk mengidentifikasi dan menganalisis pelaksanaan Peraturan Daerah dalam penanggulangan masalah gelandangan dan pengemis (Gepeng) di Kecamatan Banjang Kabupaten Hulu Sungai Utara;

b. Untuk mengidentifikasi dan menganalisis kendala yang mempengaruhi keberhasilan dalam pelaksanaan Peraturan Daerah dalam Penanggulangan masalah Gelandangan dan Pengemis (Gepeng) di Kecamatan 
Banjang Kabupaten Hulu Sungai Utara.

\section{KONSEP PEMBANGUNAN}

Teori pembangunan
dalam ilmu sosial dapat
dibagi ke dalam dua
paradigma besar, modernisasi
dan ketergantungan
(Lewwellen, Larrin dan Kiely
dalam Syamsiah : 2009).
Paradigma modernisasi
mencakup teori-teori makro
tentang $\quad$ pertumbuhan
ekonomi dan perubahan
sosial dan teori-teori mikro
tentang nilai-nilai individu
yang menunjang proses
perubahan.
ketergantungan mencakup
teori-teori keterbelakangan
(under-development)

ketergantungan (dependent development) dan sistem dunia (world system theory). Sedangkan Tikson dalam Syamsiah : 2009 membaginya kedalam tiga klassifikasi teori pembangunan, yaitu modernisasi, keterbelakangan dan ketergantungan. Dari berbagai paradigma tersebut itulah kemudian muncul berbagai versi tentang pengertian pembangunan.

\section{IMPLEMENTASI KEBIJAKAN PUBLIK}

Keberhasilan

implementasi kebijakan akan ditentukan oleh banyak variabel atau faktor,dan masing-masing variabel tersebut saling berhubungan satu sama lain. Dalam pandangan Edwards III (dalam Subarsono, 2013 : 90) implementasi kebijakan dipengaruhi oleh empat variabel, yakni (a) komunikasi, sumberdaya, (c) disposisi, dan (d) struktur birokrasi. Keempat variabel tersebut juga saling berhubungan satu sama lain, yaitu sebagai berikut :
(a) Komunikasi
(b) Sumberdaya 
(c) Disposisi

(d) Struktur organisasi

GELANDANGAN

DAN PENGEMIS (GEPENG)

Istilah gelandangan berasal dari kata gelandangan, yang artinya selalu berkeliaran atau tidak pernah mempunyai tempat kediaman tetap (Suparlan, 1993 : 179, dalam Irsan Suandi 2015). Pada umumnya para gelandangan adalah kaum urban yang berasal dari desa dan mencoba nasib dan peruntungannya di kota, namun tidak didukung oleh tingkat pendidikan yang cukup, keahlian pengetahuan spesialisasi dan tidak mempunyai modal uang. Sebagai akibatnya, mereka bekerja serabutan dan tidak tetap, terutamanya di sektor informal.

\section{UPAYA PENANGGULANGAN GELANDANGAN DAN PENGEMIS (GEPENG)}

\author{
Menurut Perda Nomor \\ 17 Tahun 2015 tentang \\ Penanggulangan Gelandangan
}

dan Pengemis di Kabupaten Hulu Sungai Utara, yaitu antara lain :

a) Upaya preventif

Upaya pereventif ini dilakukan melalui ; penyuluhan dan bimbingan sosial; (2) pembinaan sosial; (3) bantuan sosial; perluasan kesempatan kerja; (5) pemukiman lokal; peningkatan derajat kesehatan; dan/atau (7) peningkatan pendidikan.

b) Upaya responsif

(1) Penertiban dan Pendampingan Penertiban adalah suatu proses kegiatan dan cara untuk menjadikan para Gelandangan dan Pengemis (Gepeng) taat pada aturan yang berlaku dengan senantiasa mempertimbangkan aspek hak azasi manusia..

(2) Penampungan sementara adalah tempat pelayanan yang memiliki tugas dan 
fungsi tempat tinggal sementara dan memberikan rasa aman sebelum mendapat rujukan.

(3) Pengembalian ke keluargaan dan masyarakat adalah proses pengembalian Gelandangan dan Pengemis (Gepeng) kepada orangtua/wali/keluarga/ka mpong halamannya, dan dapat diberikan bantuan sosial sesuai ketentuan yang berlaku.

c) Upaya rehabilitatif yang dilakukan melalui ;

(1) Bimbingan fisik;

(2) Bimbingan mental;

(3) Bimbingan sosial;

(4) Bimbingan keterampilan;

(5) Pemberian jaminan sosial;

(6) Resosialisasi/reintegrasi sosial. 


\section{KERANGKA BERPIKIR}

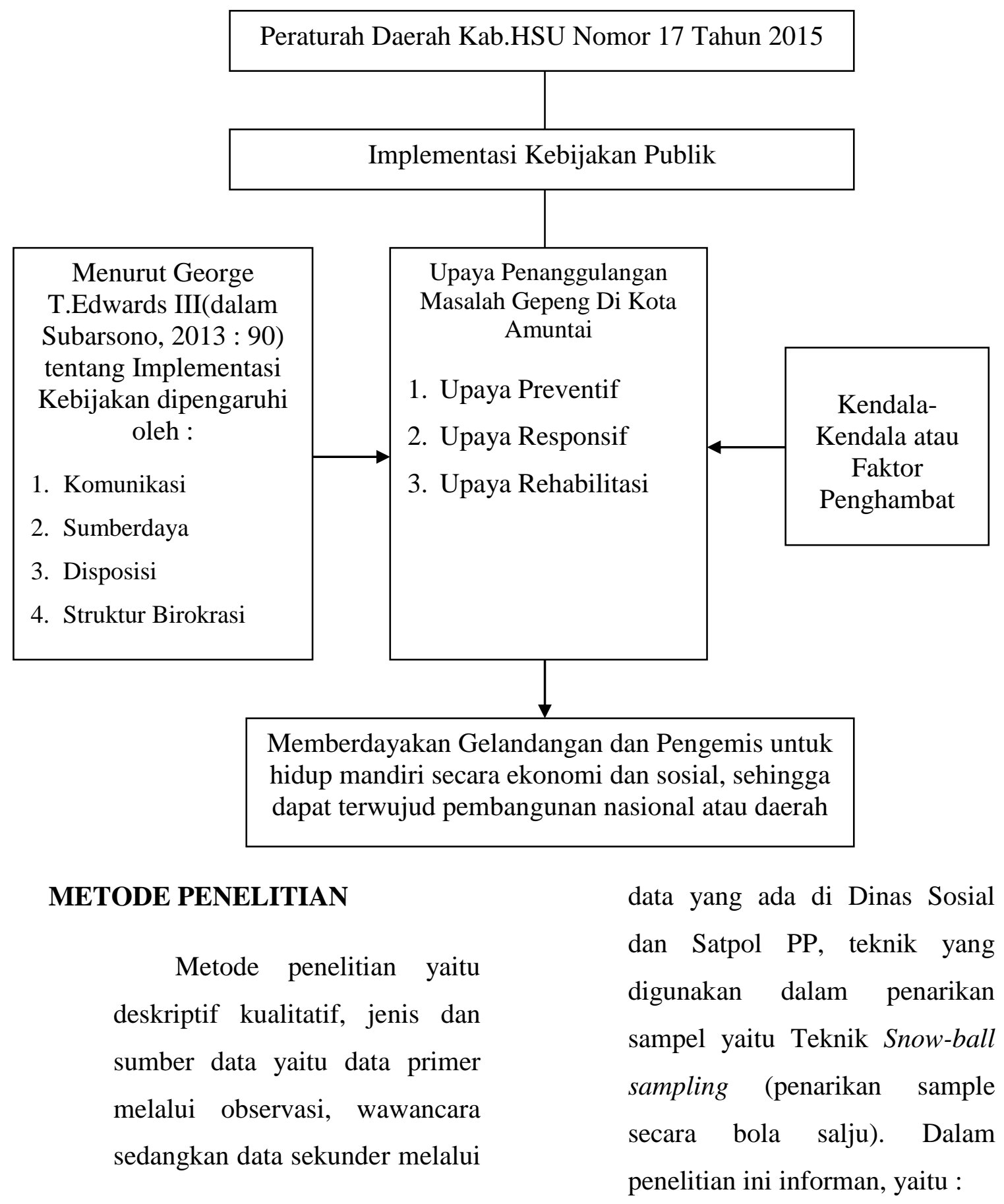

Siti Raudah | Implementasi Peraturan ..... | 102 
1. Kepala Dinas Sosial

2. Kabid Rehabilitasi Sosial (Dinas Sosial Kab.HSU)

3. Kasi Rehabilitasi Tuna Sosial dan Perdagangan Orang (Dinas Sosial Kab.HSU)

4. Satpol PP

5. Anak Jalanan / Gepeng

6. Masyarakat

Jumlah
$1 \quad$ Orang

$1 \quad$ Orang

1 Orang

2 Orang

3 Orang

2 Orang

$10 \quad$ Orang
HASIL DAN PEMBAHASAN

1. Implementasi Peraturan

Daerah Nomor 17 Tahun 2015

Tentang

Upaya

Penanggulangan Masalah

Gelendangan dan Pengemis Di

Kecamatan

Banjang

Kabupaten Hulu Sungai

Utara

\section{a. Komunikasi}

Dalam sebuah pelaksanaan

kebijakan yaitu mengenai penerapan

Peraturan Daerah Nomor 17 Tahun

2015 tentang Upaya Penanggulangan

Masalah Gelandangan dan Pengemis

(Gepeng), hal ini sudah dilakukan oleh

Dinas Sosial melalui koordinasi dengan Satpol PP untuk merazia para

Gepeng tersebut kemudia diberikan

sebuah somasi atau bahkan

berinteraksi dengan para Gelandangan

tersebut. Yang kami butuhkan kata

Bapak H. Halida yang terkait masalah

penanggulangan ini adalah Rumah

Singgah hanya saja kami untuk sementara hanya bisa melakukan Upaya Preventif saja yaitu memberikan sosialisasi, berinteraksi, bimbingan secara memberikan pemahaman bahwa di Kota Amuntai sudah dikeluarkan Peraturan Daerah tentang penanggulangan Gelandangan dan Pengemis. 
Kemudian hal tersebut juga di utarakan oleh Bapak Padliannoor, anggota Satpol PP, setelah kami razia atau patroli para gelandangan dan pengemis tersebut kami beri sedikit bimbingan dan pengertian bahwa jangan lagi melakukan hal mengenai mengemis. Jadi untuk hal berkomunikasi atau berinteraksi yang sesuai dengan Upaya Preventif sudah kami lakukan, yaitu memberikaan bimbingan.

\section{b. Sumber Daya}

Untuk melaksanakan Peraturan Daerah ini memerlukan yang namanya sumber daya, namun sumber daya yang ada hanya terkait masalah sumber daya manusianya saja dalam melakukan upaya preventif, yaitu melakukan pembinaan, sosialisasi serta interaksi, kemudian kalau masalah upaya responsif yaitu melakukan Penertiban adalah suatu proses kegiatan dan cara untuk menjadikan para Gelandangan dan Pengemis (Gepeng) taat pada aturan yang berlaku dengan senantiasa mempertimbangkan aspek hak azasi manusia sudah dilakukan. Sedangkan Penampungan tersebut kami masih belum memiliki, jadi sumber daya dalam melakukan pelaksanaan peraturan daerah ini hanya sebatas melalui pemberian pemahaman dan penertiban.

\section{c. Disposisi}

$$
\text { Pendelegasian tugas }
$$
sebagai implementor yaitu Dinas Sosial dan berkoordinasi dengan Satpol PP serta Kepolisian yang ada di Banjang Kabupaten Hulu Sungai Utara sudah dilaksanakan, kemudian melakukan penertiban gabungan, tapi untuk saat ini jarang dilakukan. Namun kalau bagian Penertiban dan Patroli di Satpol PP selalu melakukannya, dan kami punya 
kelompok kata Bapak Padlianoor, kelompok kami di bagi 3 (Tiga), setiap kelompok ada 10 (sepuluh) orang jadi kami mendelegasikan tugas kami secara teratur. Dinas Sosial hanya menerima kabar dari kami apabila ada tertangkap tangan para gelandangan dan pengemis tersebut kena patrol dan kami bawa langsung ke kantor kami dan diberikan pembinaan yang kemudian kami adakaan pemulangan. Karena Dinas Sosial hanya fasilitator saja.

\section{d. Struktur Birokrasi}

Dalam melakukan upaya penanggulangan masalah gelandangan dan pengemis ini, Dinas Sosial dan Satpol PP Standar Operasional Prosedur (SOP) kami mengacu pada Peraturan Daerah Nomor 17 Tahun 2015 tentang Upaya Penanggulangan Masalah Gelandangan dan Pengemis, sehingga kami tidak ada yang namanya penyimpangan.
Karena semua hal mengenai upaya penanggulangan masalah gelandangan dan pengemis ini terdapat dalam Peraturan tersebut kami hanya melaksanakannya saja lagi. Ungkapnya Ibu Rahmiati Kabid Rehabilitasi Sosial.

2. Kendala-kendala dalam mengimplementasikan

Peraturan Daerah

Nomor 17 Tahun 2015 tentang Upaya

Penanggulangan Masalah

Gelandangan dan Pengemis

\section{di Banjang}

a. Kurangnya Dana

b. Kurangnya sarana dan prasarana pendukung

c. Kurangnya perhatian dari Pemerintah Daerah

\section{PENUTUP}

Kesimpulan

Dalam implementasi Peraturan Daerah Nomor 17 Tahun 2015 tentang Penanggulangan masalah Gelandangan dan Pengemis di Kota Amuntai 


\begin{abstract}
Kabupaten Hulu Sungai Utara, masih belum sepenuhnya dijalankan hal ini terlihat dimana rumah singgah untuk penampungan anak jalanan dan gelandangan tidak dibangun padahal inilah upaya dalam menanggulangi masalah maraknya para Gelandangan dan Pengemis tersebut. Namun pembinaan secara persuasif sudah dilakukan oleh Dinas Sosial dan Satpol PP di saat menjaring atau patroli untuk penertiban para anak jalanan tersebut.
\end{abstract}

Kemudian kendala yang dihadapi dalam implementasi ini adalah mengenai masalah dana itulah yang menyebabkan tidak adanya rumah singgah untuk penampungan para Gelandangan dan Pengemis dalam hal pembinaan secara rutin. Selain itu juga kurangnya sarana dan prasarana pendukung seperti rumah singgah tersebut menjadi kendala dalam menanggulangi, serta kurangnya perhatian Pemerintah Daerah dalam memberikan anggaran dana untuk melakukan lebih lanjut upaya penanggulangan masalah gelandangan dan pengemis yang ada di Kota Amuntai sehingga pembangunan daerah tidak sepenuhnya berjalan dengan baik.

\section{DAFTAR PUSTAKA}

\section{Buku-buku}

Fischer, Frank. Miller, Gerald.J. Sidney, Mara.S. 2015. Hand Book Analisis Kebijakan Publik (Teori, Politik dan Metode). Bandung. Nusa Media.

Moelong, Lexy. J. 2007. Metodologi Penelitian Kualitatif. Bandung: PT Remaja Rosdakarya.

Safi'I, H. M. Dr., M.Si. 2007. Strategi dan Kebijakan Pembangunan Ekonomi 
Daerah (Perspektif

Teoritik). Kandangan.

Averroes Press.

Siagian, Sondang. P. Prof.Dr., M.P.A. 2005.

Administrasi Publik

(Konsep, Dimensi dan

Strateginya). Jakarta.

Bumi Aksara.

Subarsono, AG.Drs.,M.Si.,MA.

2013. Kebijakan Publik

(Konsep, Teori, dan

Aplikasi). Yogyakarta.

Pustaka Pelajar.

Sugiyono. 2011. Metode

Penelitian Kuantitatif

Kualitatif dan R\&D.

Bandung: Alfabeta.

Winarno,

Budi.

Prof.Drs.MA.PhD.

2014. Kebijakan Publik,

Teori, Proses, dan Studi

Kasus. Yogyakarta. PT.

Buku Seru.

\section{Peraturan-peraturan}

Peraturan Daerah Kabupaten

Hulu Sungai Utara

Nomor 17 Tahun 2015,

Tentang

Penanggulangan

Masalah Gelandangan

dan Pengemis.

\section{Jurnal}

Junaidi, Robby Kurniawan. 2014. "Evaluasi

Pelaksanaan Kebijakan

Tentang Penertiban dan

Pembinaan

Gelandangan dan

Pengemis Di Kota

Pekanbaru (Studi

Peraturan Daerah

Nomor 12 Tahun

2008)”. Jurnal Ilmu

Administrasi Negara -

Prodi Administrasi

Negara Fakultas Ilmu

Sosial dan Ilmu Politik. 


\begin{tabular}{|c|c|c|}
\hline & Universitas & Ilmu Administrasi \\
\hline & Volume 1 Nomor 2. & Negara $\quad-$ \\
\hline & & Administrasi Negara \\
\hline & & Fakultas Ilmu Sosial \\
\hline Setiawan, & Erwan. & Politik. \\
\hline & 'Pelaksanaan Prinsip- & Universitas \\
\hline & Prinsip Penanganan & Mulawarman. Volume 1 \\
\hline & Gelandangan & Nomor 4. \\
\hline & Pengemis & \\
\hline & Penertiban Di Kota & \\
\hline & Pekanbaru”. $\quad$ Jurnal & Internet \\
\hline & Imu Administrasi & \\
\hline & Negara $\quad-\quad$ Prodi & Badruddin, Syamsiah., "Teori \\
\hline & Administrasi Negara & dan Indikator \\
\hline & Gakultas Ilmu Sosial & Pembangunan", diakses \\
\hline & lan Ilmu Politik. & dari \\
\hline & Universitas & https://profsyamsiah.wo \\
\hline & Volume 1 Nomor 2. & $\underline{\text { rdpress.com. }} \underline{19 \text { Maret, }}$ \\
\hline & & 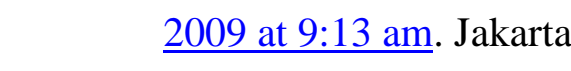 \\
\hline Anggraini & i, $\quad$ Lisa $\quad$ Yulianti & \\
\hline & Kusuma. $\quad 2013$. & Edi. 2016. Makalah \\
\hline & 'Evaluasi Pelaksanaan & Gepeng dan PSK. \\
\hline & Peraturan & Rabu, 10 Februari 2016. \\
\hline & Perda) Kota Samarinda & \\
\hline & Nomor 16 Tahun 2002 & http://www.hulusungaiutara.bps. \\
\hline & Penertiban & go.id. "Kabupaten Hulu \\
\hline & Gelandangan & Sungai Utara Dalam \\
\hline & Pengemis Di Kota & Angka 2016” , 2016. \\
\hline & Samarinda". & Amuntai. \\
\hline
\end{tabular}


Mahesa, Ragita. 2013. Gepeng. Agitera.blogspot.co.id.

18 November 2013. Jakarta.

Satria, Ase. 2015. "Definisi Implementasi Dan Teori Implementasi Oleh Para Ahli Di Dalam Sebuah Kebijakan”.

http://www.materibelaja r.html. Jakarta.

Suandi, Irsan. 2015. Makalah Gelandangan dan Pengemis.

Andisuwandirsan.blogs pot.com. 9 April 2015.

Teguh. 2017. "Pengertian Implementasi Menurut Para Ahli, KBBI, Beserta Contohnya”. http://www.satujam.co

m. 2 Agustus 2017. Jakarta.
Times Line Indonesia Kab. HSU. 2017. Atasi Gepeng, HSU Butuh Rumah Singgah. Amuntai. Rabu, 12 April 2017 Jam 10 : 14. 